\title{
An 11-bp duplication in the promoter region of the VHL gene in a patient with cerebellar hemangioblastoma and renal oncocytoma
}

\author{
Lucia Anna Muscarella $\cdot$ Raffaela Barbano $\cdot$ Bartolomeo Augello · \\ Vincenza Formica · Lucia Micale · Leopoldo Zelante · Leonardo D'Agruma • \\ Giuseppe Merla
}

Received: 21 November 2006/ Accepted: 11 March 2007/Published online: 17 April 2007

(C) The Japan Society of Human Genetics and Springer 2007

\begin{abstract}
Central nervous system hemangioblastomas are benign vascular tumours that may present sporadically or as manifestation of the von Hippel-Lindau (VHL) disease. VHL Syndrome is a rare autosomal dominant disorder characterized, besides hemangioblastomas, by susceptibility to multifocal and bilateral renal cell carcinoma and cysts, retinal angiomas, pheochromocytoma, epididymis cystoadenoma, pancreatic cysts and/or islet cell tumours. Germline mutations of VHL tumour suppressor gene cause the VHL disease, while somatic mutations have been associated with sporadic hemangioblastomas and clear-cell renal carcinomas. We identified an 11-bp duplication in the promoter region of the VHL gene in a VHL-affected individual. Functional analysis revealed that this variant affects the binding or the binding affinity of one or more transcription factors that regulate the transcription of $V H L$ in vivo, reducing the endogenous levels of $V H L$ mRNA. Moreover, consistent with the "two hits" model, microsatellite analysis of hemangioblastoma tissue from this patient revealed Allelic Imbalance for the chromosomal region near the $V H L$ gene. We propose that these molecular events, through a loss of pVHL function, lead to the onset of the VHL-related tumours in that individual.
\end{abstract}

Keywords von Hippel Lindau · Hemangioblastomas . Allelic imbalance $\cdot$ qPCR $\cdot$ EMSA

L. A. Muscarella $\cdot$ R. Barbano $\cdot$ B. Augello .

V. Formica · L. Micale $\cdot$ L. Zelante · L. D'Agruma .

G. Merla $(\bowtie)$

Servizio Genetica Medica, IRCCS "Casa Sollievo della

Sofferenza”, Poliambulatorio “Giovanni Paolo II,

Viale Padre Pio, 71013 San Giovanni Rotondo, Italy

e-mail: g.merla@operapadrepio.it

\section{Introduction}

von Hippel-Lindau syndrome is a heritable autosomal dominant syndrome predisposing to central nervous system (CNS) and retinal hemangioblastomas, clear-cell renal carcinomas and pheochromocytomas (Choyke et al. 1995; Clifford and Maher 2001; Linehan et al. 1995; Maher and Kaelin 1997). Other lesions associated with VHL syndrome include multiple renal and pancreatic cysts, endolymphatic sac tumours of the inner ear, neuroendocrine tumours, oncocytomas, and epididymal and broad ligament cystadenomas (Choyke et al. 1997; Maher and Kaelin 1997; Manski et al. 1997). The disease affects approximately 1:36,000 live births with over $90 \%$ penetrance by 65 years of age (Maddock et al. 1996).

The VHL gene (NM_000551) located on chromosome 3p25-26 is widely expressed in both fetal and adult tissues (Latif et al. 1993; Richards et al. 1996) and is well conserved throughout evolution (Woodward et al. 2000). The VHL gene encodes two protein isoforms of 213 and 160 amino acid residues, respectively, with a predominantly cytoplasmic localization (Lee et al. 1996).

Most VHL index cases that are positive for VHL mutations have a positive family history of the disease. However, de novo mutations have been reported in some individuals without any VHL history in their parental lineage (Glenn et al. 1999).

Genotype-phenotype correlations have been well established on the types of mutation in the VHL gene and the specialized clinical features of the disease (Friedrich 2001; Gallou et al. 2004).

Here, we describe preliminary functional characterization of a novel 11-bp duplication located in a regulatory site of the $V H L$ promoter region in a patient with cerebellar hemangioblastoma and renal oncocytoma. 


\section{Materials and methods}

Human samples and clinical data

The affected individual was a 40-year-old male who came to our attention because of symptomatic cerebella hemangioblastoma diagnosed by magnetic resonance imaging scan. There was no indication of a family history for this phenotype. Total removal of the lesion by surgery was achieved, with improvement of the neurological status. Paraffin-embedded tissues from the excised lesion were collected. The tumour sample was histopathologically diagnosed as hemangioblastoma according to the criteria of the World Health Organization (Kleihues and Cavenee 2000)

As the presence of a hemangioblastoma is the first clinical manifestation of the disease in approximately $40 \%$ of patients with VHL, our patient had undergone clinical and abdominal ultrasonography for other VHL-related tumours. This analysis showed the presence of a left kidney oncocytoma, a very rare clinical manifestation associated with the disease (Fiske et al. 2005; Teh et al. 1998).

Clinical available records reported the presence of renal cysts in the mother of the proband, whereas one of his siblings (36 years old) presented two right epididymal cysts. Finally, a second sibling (42 years old) does not show any evident clinical manifestation of the disease.

Sample preparation and mutational analysis

After written informed consent, genomic DNA was extracted from peripheral blood leukocyte (PBL) and from surgically excised paraffin-embedded cerebella hemangioblastoma using standard phenol-chloroform procedure and QIAamp DNA Mini Kit (Qiagen), respectively.

The entire $V H L$ coding sequence and promoter region were PCR amplified using the set of primers listed in Table 1. PCR products were purified $\left(\mathrm{GFX}^{\mathrm{TM}}\right.$ PCR DNA and Gel Band Purification Kit [GE Healthcare]) and sequenced.

The PCR promoter region fragment was subcloned using TOPO TA cloning vector (Invitrogen), amplified directly from crude lysates of single bacterial colonies, and examined by MspI restriction enzyme digestion and scored as either wild type or mutant depending on fragment sizes. Normal allele produces six fragments of 118, 72, 65, 30, 5 and 4-bp in size, while allele with duplication produces a 129-bp fragment instead of the 118-bp fragment. The presence of the $V H L$ promoter variant was ascertained in a collection of 250 healthy blood donors without family history of VHL disease or related symptoms. The control samples were recruited from Southern Italy and analyzed by $M s p$ I restriction digestion.
VHL gene deletions analysis

Analysis of genomic deletions of the $V H L$ gene was performed in Long PCR by using a set of primers' pairs described in (Cybulski et al. 1999). Briefly, large fragments were amplified in a final volume of $25 \mu \mathrm{l}$ using $2 \mathrm{U}$ of Expand Long Template Enzyme (Roche), 20 pm of each primer, $500 \mu \mathrm{M}$ dNTPs and $400 \mathrm{ng}$ of template DNA.

\section{$\mathrm{LOH}$ analysis}

PBL and tumour DNA samples were analyzed using fluorescently-labelled polymorphic microsatellite markers (Table 1). Independent PCR amplifications were performed in duplicate as described in Kuroki et al. (2003) and PCR products were detected by capillary electrophoresis. The results were analyzed by the Prism Genescan software and then exported by Prism Genotyper Analysis software (Livak and Schmittgen 2001) for semi-automatic allelic imbalance estimation. Semi-quantitative expression $\left(Q^{\mathrm{LOH}}\right)$ for the degree of imbalance was calculated as described in Skotheim et al. (2001) (see also Fig. 2).

Electrophoretic mobility shift assay (EMSA)

EMSAs were performed using the Gel Shift Assay System Kit (Promega). Double-stranded DNA probes containing either the wild type (wt) or the 11-bp variant (see below) were end-labelled with $\gamma 32 \mathrm{P}$ (ATP) using T4 polynucleotide kinase (Promega), incubated with HeLa nuclear extract (Promega) and separated on a $4 \%$ nondenaturating acrylamide gel. Competition assays were carried out using unlabeled probes with the indicated fold molar excess. Band intensities were analyzed and quantified with autoradiography and PhosphoImager (Molecular Image FX, Biorad), respectively.

The nucleotide sequences used are as follows: 5'AGCGCGCACGCAGCTCCGCCCCGCGTCCGACCCGCGGAT-3' for the wild type and 5'AGCGCGCACGCAGCT CCGCCCGCGTCCGCCCCGCGTCCGACCCGCGGAT$3^{\prime}$ for the 11-bp variant, respectively.

Reporter luciferase assay

The -175 to -35 sequence of wild type and 11-bp variant of VHL promoter was cloned into pGL3 basic vector (Promega). HeLa cells were transfected with $800 \mathrm{ng}$ of pGL3 basic, pGL3 basic wt VHL and pGL3 basic variant VHL constructs using Fugene6 (Roche) according to the manufacturer's instructions. $10 \mathrm{ng}$ of pRL-SV40 (Promega) was added to measure transfection efficiency. At $24 \mathrm{~h}$ posttransfection, cells were harvested and luciferase activity was measured by Dual Luciferase Reporter Assay System 
Table 1 Primer sequences for VHL gene amplification and $\mathrm{LOH}$ analysis

\begin{tabular}{|c|c|c|}
\hline Exon & Primer name & Primer sequences $\left(5 \rightarrow 3^{\prime}\right)$ \\
\hline \multirow[t]{2}{*}{ Promoter } & 5'UTR-prom_fw & TAGCCTCGCCTCCGTTACAA \\
\hline & 5'UTR-prom_rv & TTCTTCAGGGCCGTACTCTTCGA \\
\hline \multirow[t]{4}{*}{1} & VHL-ex1a_fw & GTCTGGATCGCGGAGGGAAT \\
\hline & VHL-ex1a_rv & GGACTGCGATTGCAGAAGAT \\
\hline & VHL-ex1b_fw & TGCGCTCGGTGAACTCGCGCGA \\
\hline & VHL-ex1b_rv & TTCAGACCGTGCTATCGTCC \\
\hline \multirow[t]{2}{*}{2} & VHL-ex2_fw & CACCGGTGTGGCTCTTTAAC \\
\hline & VHL-ex2_rv & TGGGCTTAATTTTTCAAGTGG \\
\hline \multirow[t]{2}{*}{3} & VHL-ex3_fw & GCAAAGCCTCTTGTTCGTTC \\
\hline & VHL-ex3_rv & CCATCAAAAGCTGAGATGAAA \\
\hline \multirow[t]{12}{*}{ Flanking } & D3S1335_F & AAGGCACTGAGGAGATGAGA \\
\hline & D3S1335_R & TAGGAAAATTAGACGGAAGCAA \\
\hline & D3S1317_F & TACAAGTTCAGTGGAGAACC \\
\hline & D3S1317_R & CCTCCAGGCCATACACAGTCA \\
\hline & D3S1038_F & TCCAGTAAGAGGCTTCCTAG \\
\hline & D3S1038_R & AAAGGGGTTCAGGAAACCTG \\
\hline & D3S3950_F & САТССТССТTTTTATTTCAAGAGG \\
\hline & D3S3950_R & ACAGAGTGGCAAGCTTTGGA \\
\hline & D3S1304_F & TTCGCTCTTTGATAGGC \\
\hline & D3S1304_R & ATTTCATTTGTAATTTACTAGCAG \\
\hline & D3S1263_F & CTGTTGACCCATTGATACCC \\
\hline & D3S1263_R & TAAAATCACAGCAGGGGTTC \\
\hline \multirow[t]{4}{*}{ LOH control marker } & D1S2836_F & TTTAACCAAGGNGGTGAAAG \\
\hline & D1S2836_R & CTGGAATGAAATCCTCCC \\
\hline & D2S125_F & GCAACAGAGTGAGACCCTGA \\
\hline & D2S125_R & TTCTGAGAACCAGATTGTGATTG \\
\hline \multirow[t]{8}{*}{ qPCR } & EEF1A1_for & AGCAAAAATGACCCACCAATG \\
\hline & EEF1A1_rev & GGCCTGGATGGTTCAGGATA \\
\hline & GAPDH_for & GAAGGTGAAGGTCGGAGTC \\
\hline & GAPDH_rev & GAAGATGGTGATGGGATTTC \\
\hline & HPRT1_for & TGACACTGGCAAAACAATGCA \\
\hline & HPRT1_rev & GGTCCTTTTCACCAGCAAGCT \\
\hline & VHL_for & GGCCGCCGCATCCA \\
\hline & VHL_rev & CATCGTGTGTCCCTGCATCTC \\
\hline
\end{tabular}

SuperMix-UDG (Invitrogen) and run on ABI 7900 sequence detection system with the defaults amplification conditions. The geometric mean of $\mathrm{Ct}$ values of GAPDH (NM_002046), EEF1A1 (NM_001402) and HPRT1 (NM_000194) genes were used to normalize input for each sample analyzed, while ten control cDNAs were used to define normal relative expression levels. The calculations were made using the comparative CT method as reported (User Bulletin \#2, Applied Biosystems; Livak and Schmittgen 2001; Vandesompele et al. 2002).

Binding sites prediction and statistical methods

To predict and compare binding sites in alternative alleles we used Alibaba2 (http://www.gene-regulation.com/) and 
TESS interface (http://www.cbil.upenn.edu/tess/), respectively.

The $t$ test for independent samples was used as statistical method.

\section{Results and discussion}

Germline inactivation of the VHL gene causes the von Hippel-Lindau cancer-predisposing syndrome, and somatic mutations of this gene have been associated to sporadic hemangioblastoma and clear-cell renal carcinoma. The entire coding sequence and the promoter region of the VHL gene in peripheral blood and cerebellar hemangioblastoma was analyzed in an individual that presented a symptomatic cerebella hemangioblastoma and a left kidney oncocytoma.

A heterozygous (ca. -44_-54dup11) 11-bp duplication was identified in the $V H L$ promoter region 65 bp upstream from the start codon (hereafter referred to as the 11-bp variant) in both patient tissues examined (Fig. 1a). No other nucleotide change was detected and Long PCR to detect genomic deletions was negative confirming that the 11-bp duplication was the only variant found in the patient.

The same variant was absent in 250 healthy unrelated blood donors analyzed by MspI restriction digestion, as described in Materials and methods, confirming its absence in the general population (data not shown).

Genetic analysis of other available family members showed that the variant is present in both the siblings of propositus. The mother was negative for the 11-bp duplication, while the DNA of the father was not available. The father died of lung cancer without any evident signs of VHL disease, and thus we were unable to draw the familial inheritance of this variant although a paternal transmission might be highly likely. Interestingly, one of the sibling positive for the 11-bp variant shows no evident VHL-related clinical manifestation after instrumental VHL disease protocol screening (Catapano et al. 2005). This aspect could be explained by the low penetrance of this variant, both with respect to late disease onset and predisposition to benign tumours. In fact, there is a large variability in the age onset of this disorder, and environmental factors and genetic modifiers influence the phenotypic expression of the disease (Glenn et al. 1991; Stolle et al. 1998; Webster et al. 1998).

The 11-bp variant is located in a regulatory region that affects VHL promoter activity (Kuzmin et al. 1995; Zatyka et al. 2002). Analysis of this region using different bioinformatics algorithms revealed several multiple predicted binding sites for transcription factors (TFs) in agreement with previous reports (Zatyka et al. 2002). Thus, the duplication of this region could result in altered transcriptional regulation. In order to investigate this possibility, electrophoretic mobility shift assays (EMSAs) were carried out. HeLa nuclear extracts were incubated with end-labelled double-stranded oligonucleotides containing the 11bp variant and increasing amounts of either unlabeled wild type or 11-bp variant probes as competitors. As depicted in Fig. 1b, the unlabeled wild-type competitor bound the HeLa nuclear extract with greater affinity than the unlabeled 11-bp variant competitor as demonstrated by the statistically significant reduced intensity of the radiolabelled HeLa-DNA complex at equivalent competitor concentrations [Fig. 1b, compare lane 3 with $7(P$ value $<0.01)$ and lane 4 with $8(P$ value $<0.01)$, respectively]. Similar differences were obtained when the radiolabelled wild type sequence was used as probe instead of the variant sequence (data not shown).

Biocomputational analysis revealed that $\mathrm{Sp} 1$ was one of the several transcriptional factors putatively binding to the duplicated region. Thus, in order to investigate whether the observed EMSA patterns were due to differential Sp1 binding efficiency, EMSA competition experiments were performed using labelled wild type and 11-bp variant probes with increasing amounts of unlabelled Sp1 canonical sequence. Interestingly, we did not find any significant difference in Sp1 mediated competition (data not shown) suggesting that the $\mathrm{Sp} 1$ sites are probably not responsible for the different binding affinity observed in HeLa in our experimental conditions, supporting the hypothesis that the binding of other proteins could be involved.

The location within the promoter suggests that the 11-bp variant can influence the $V H L$ promoter activity. To ascertain this, we performed Luciferase Reporter Assay using wild-type and mutated VHL promoter sequences in HeLa cells. As reported in Fig. 1c, the 11-bp variant construct produced a significant $(P<0.01)$ decrease of luciferase activity compared with the wt construct, suggesting that the duplication influences VHL promoter activity.

In addition, to get insight on the possible physiological consequences of this novel promoter variant in the context of full-length promoter, quantitative real-time PCR was carried out to determine the mRNA expression level of $V H L$ in PBL cDNAs from the propositus and ten healthy controls. As reported in Fig. 1d, the affected individual showed a significantly lower mRNA expression level of $V H L$ compared to the average of ten healthy independent controls ( $P$ value 0.0009$)$. It is worth underlining that the value of the healthy control with the lowest mRNA expression level is significant higher than that of the propositus $(P<0.04)$.

Assessing the VHL mRNA expression level in the relatives it would be of great interest to define whether this mutation is functional. However, the impossibility of obtaining RNA samples from these individuals precluded this analysis. 
a
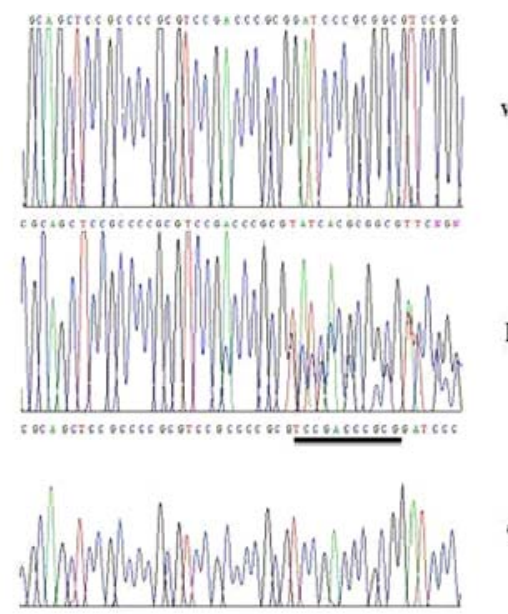

cloned 11 bp variant

b
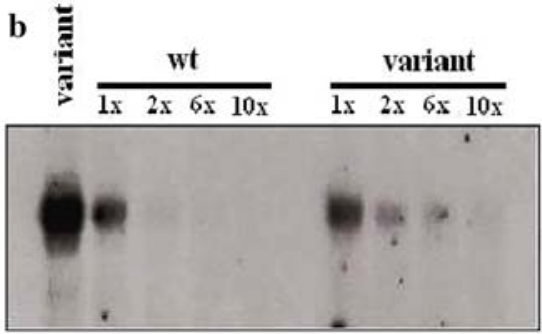

$\begin{array}{lllllllll}1 & 2 & 3 & 4 & 5 & 6 & 7 & 8 & 9\end{array}$
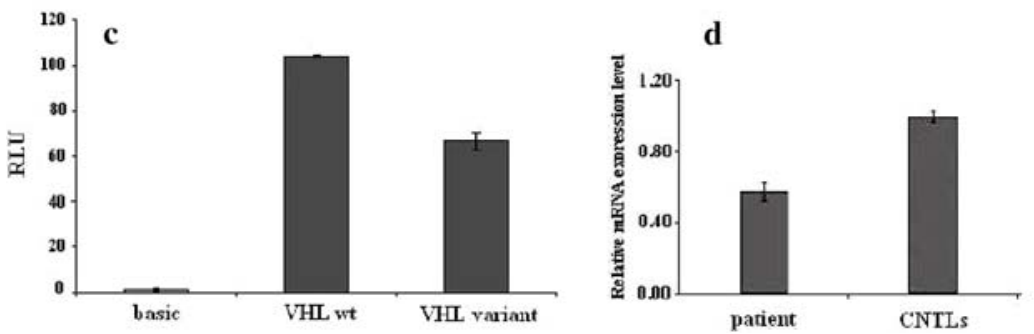

Fig. 1 Effect of the VHL promoter variant on transcriptional activity. a Representative sequence electropherogram of direct sequencing of PCR product illustrating the sequence of VHL promoter region in the wild type ( $w t)$ and mutated alleles. At the bottom, a cloned product of mutated allele was also reported. The 11-bp duplicated sequence is marked by the bar drawn below the sequence. b Different binding ability of wild type and variant sequence for HeLa nuclear extract. Representative electrophoretic mobility shift assay is depicted in which HeLa cell nuclear extract was incubated with radiolabelled 11bp variant sequence. Competition experiments were done in the presence of the indicated fold molar excess of unlabelled wt or variant sequences. The experiments were performed three times with similar results. c Decrease of relative luciferae activity (RLA) of 11-bp variant construct compared with wt construct. The luciferase activity values have been normalized to the level of activity obtained with pGL3 basic vector. d Decrease of endogenous VHL mRNA expression level in the propositus. Average relative mRNA expression level from affected and controls as measured by real-time quantitative PCR. The average of expression levels from ten healthy independent controls is reported. All values have been normalized to the level of GAPDH, EEF1A1 and HRPT1
In carriers of $V H L$ gene germline mutations, the development of the disease begins following the loss or inactivation of the remaining wild type allele according to the Knudson two-hit model (Knudson 1971; Linehan et al. 2001). Several possible mechanisms have been reported to lead to inactivation of the second allele, such as cytogenetic abnormalities (Lemeta et al. 2002), loss of heterozygosity (LOH) (Crossey et al. 1994; Tse et al. 1997) and small intragenic mutations or hypermethylation (Glasker et al. 2001; Prowse et al. 1997).

To assess whether $\mathrm{LOH}$ was the mechanism leading to the inactivation of second $V H L$ allele, $\mathrm{LOH}$ analysis was performed on several cerebellar hemangioblastoma sections using the set of microsatellites listed in Table 1. Different tumour-rich fractions of hemangioblastoma tissue of the affected individual showed slightly variable values 
Fig. 2 Allelic imbalance $(A I)$ in haemangioblastoma tissue. The peak heights are measured in relative fluorescence units. Two microsatellites located on chromosome 1 and 2 were used as controls. a AI of D3S1335 microsatellite marker. $Q^{\mathrm{LOH}}=[2815 / 1739] /[2436 /$ 827] $=0.55$. b AI of D3S 1038 microsatellite marker. $Q^{\mathrm{LOH}}=[1494 / 956] /[1653 /$ $584]=0.55$ a) D3S1335 marker
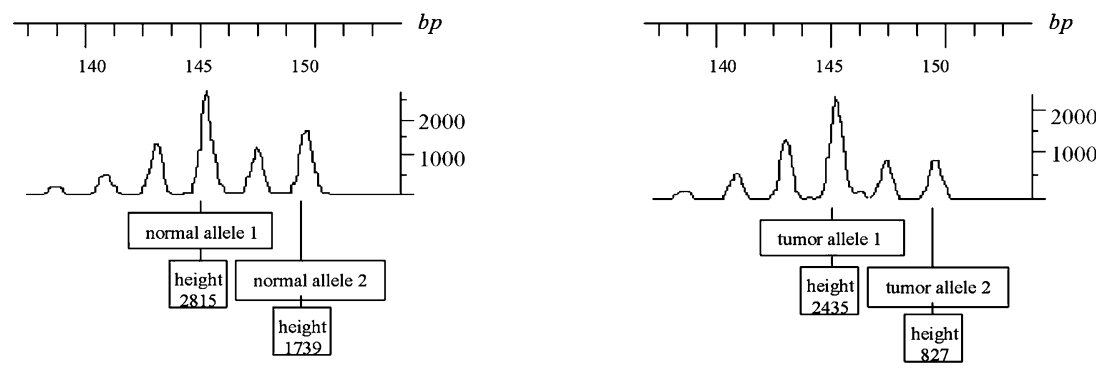

b) D3S1038 marker
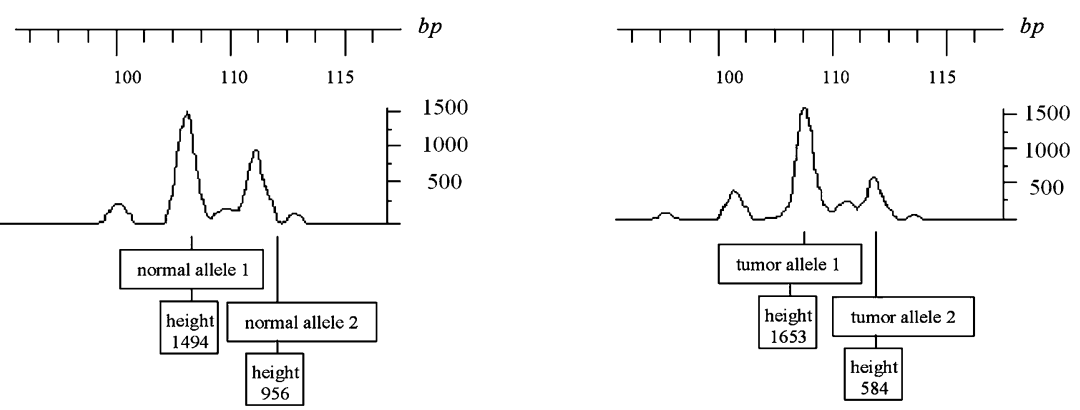

$$
\mathrm{Q}^{\mathrm{LOH}}=\frac{\text { normal allele } 1 / \text { normal allele } 2}{\text { tumour allele1/tumour allele2 }}
$$

of Allelic Imbalance for the D3S1335 and D3S1038 microsatellites located near to the VHL gene (see Fig. 2 for a representative example). Allelic imbalance describes the detection of a skewed intensity ratio between two alleles at a locus. It may reflect the complete loss of one allele that is masked by the presence of normal cells, by tumour heterogeneity or non-clonal loss. Consistently, it has been shown that the hemangioblastomas-associated vascular component is composed of reactive, nonneoplastic cells (Lee et al. 1998; Vortmeyer et al. 1997). Thus, our inability to detect complete $\mathrm{LOH}$ was likely due to the presence of normal tissue in the paraffin-embedded cerebella hemangioblastoma sections available.

The clinical signs of the patient reported here, namely singular CNS hemangioblastoma and renal oncocytoma, do not fit the classical definition of VHL diagnostic symptoms. Here, we showed that the analysis of the promoter region was crucial for the molecular characterization of this patient otherwise negative for $V H L$ mutation screening of the coding region. Therefore, extending the molecular analysis to include the regulatory regions of the gene may be helpful for mutational screening of patients having a "VHL-like" disorder.

In summary, the identification and functional characterization of an 11-bp variant in the promoter of the $V H L$ gene were reported in an individual affected by cerebellar hemangioblastoma and renal oncocytoma. The experimental data reported in this work support the hypothesis that this variant and Allelic Imbalance are the two events that lead to a functional alteration of $V H L$ expression causing the phenotype manifestation.

While we were submitting this work, Martella et al (2006) reported the identification of the same heterozygous variant in three individuals with VHL related lesions and 1/ 100 control individuals. Conversely to our results, the authors concluded that this variant is a neutral polymorphism based on their observation of equivalent expression levels of both alleles measured by PCR-RFLP.

Acknowledgments We are grateful to Luigi Bisceglia, Samuel Deutsch, and Alexandre Reymond for technical advice and critical reading of the manuscript. This study was supported by the Italian Ministry of Health (Ricerca Corrente 2005). The authors declare no potential conflicts of interest.

\section{References}

Catapano D, Muscarella LA, Guarnieri V, Zelante L, D'Angelo VA, D'Agruma L (2005) Hemangioblastomas of central nervous system: molecular genetic analysis and clinical management (discussion 1221). Neurosurgery 56(6):1215-1221

Choyke PL, Glenn GM, Wagner JP, Lubensky IA, Thakore K, Zbar B, Linehan WM, Walther MM (1997) Epididymal cystadenomas in von Hippel-Lindau disease. Urology 49(6):926-931 
Choyke PL, Glenn GM, Walther MM, Patronas NJ, Linehan WM, Zbar B (1995) von Hippel-Lindau disease: genetic, clinical, and imaging features. Radiology 194(3):629-642

Clifford SC, Maher ER (2001) Von Hippel-Lindau disease: clinical and molecular perspectives. Adv Cancer Res 82:85-105

Crossey PA, Foster K, Richards FM, Phipps ME, Latif F, Tory K, Jones MH, Bentley E, Kumar R, Lerman MI, others (1994) Molecular genetic investigations of the mechanism of tumourigenesis in von Hippel-Lindau disease: analysis of allele loss in VHL tumours. Hum Genet 93(1):53-58

Cybulski C, Krzystolik K, Maher ER, Richard S, Kurzawski G, Gronwald J, Lubinski J (1999) Long polymerase chain reaction in detection of germline deletions in the von Hippel-Lindau tumour suppressor gene. Hum Genet 105(4):333-336

Fiske J, Patel R, Kau E, Pappas JG, Garcia RA, Taneja SS (2005) Multifocal renal oncocytoma in a patient with Von HippelLindau mutation. Urology 66(6):1320

Friedrich CA (2001) Genotype-phenotype correlation in von HippelLindau syndrome. Hum Mol Genet 10(7):763-767

Gallou C, Chauveau D, Richard S, Joly D, Giraud S, Olschwang S, Martin N, Saquet C, Chretien Y, Mejean A, others (2004). Genotype-phenotype correlation in von Hippel-Lindau families with renal lesions. Hum Mutat 24(3):215-224

Glasker S, Bender BU, Apel TW, van Velthoven V, Mulligan LM, Zentner J, Neumann HP (2001) Reconsideration of biallelic inactivation of the VHL tumour suppressor gene in hemangioblastomas of the central nervous system. J Neurol Neurosurg Psychiatry 70(5):644-648

Glenn G, Stolle C, Sgambati M, Choyke P, Hurley K, Peterson J, Manolatos C, al e. (1999) New mutations versus silent-carrier parentsas source of first generation diagnoses in a hereditary neoplastic disorder: von Hippel-Lindau disease. Proc Am Assoc Cancer Res 40:464

Glenn GM, Daniel LN, Choyke P, Linehan WM, Oldfield E, Gorin MB, Hosoe S, Latif F, Weiss G, Walther M, others (1991) Von HippelLindau (VHL) disease: distinct phenotypes suggest more than one mutant allele at the VHL locus. Hum Genet 87(2):207-210

Kleihues P, Cavenee W (2000) Pathology and genetics of tumours of the nervous system: World Health Organization Classification of Tumours, Lyon

Knudson AG Jr (1971) Mutation and cancer: statistical study of retinoblastoma. Proc Natl Acad Sci USA 68(4):820-823

Kuroki T, Trapasso F, Yendamuri S, Matsuyama A, Alder H, Mori M, Croce CM (2003) Allele loss and promoter hypermethylation of VHL, RAR-beta, RASSF1A, and FHIT tumor suppressor genes on chromosome $3 p$ in esophageal squamous cell carcinoma. Cancer Res 63(13):3724-3728

Kuzmin I, Duh FM, Latif F, Geil L, Zbar B, Lerman MI (1995). Identification of the promoter of the human von Hippel-Lindau disease tumor suppressor gene. Oncogene 10(11):2185-2194

Latif F, Tory K, Gnarra J, Yao M, Duh FM, Orcutt ML, Stackhouse T, Kuzmin I, Modi W, Geil L, others (1993) Identification of the von Hippel-Lindau disease tumor suppressor gene. Science 260(5112):1317-1320

Lee JY, Dong SM, Park WS, Yoo NJ, Kim CS, Jang JJ, Chi JG, Zbar B, Lubensky IA, Linehan WM, others (1998) Loss of heterozygosity and somatic mutations of the VHL tumor suppressor gene in sporadic cerebellar hemangioblastomas. Cancer Res 58(3):504-508

Lee S, Chen DY, Humphrey JS, Gnarra JR, Linehan WM, Klausner RD (1996) Nuclear/cytoplasmic localization of the von HippelLindau tumor suppressor gene product is determined by cell density. Proc Natl Acad Sci USA 93(5):1770-1775

Lemeta S, Aalto Y, Niemela M, Jaaskelainen J, Sainio M, Kere J, Knuutila S, Bohling T (2002) Recurrent DNA sequence copy losses on chromosomal arm 6q in capillary hemangioblastoma. Cancer Genet Cytogenet 133(2):174-178
Linehan M, Zbar B, Klausner R (2001) The metabolic and molecular basis of inherited disease. In: Renal carcinoma, 8th edn. McGraw-Hill, New York, pp 907-929

Linehan WM, Lerman MI, Zbar B (1995) Identification of the von Hippel-Lindau (VHL) gene. Its role in renal cancer. JAMA 273(7):564-570

Livak KJ, Schmittgen TD (2001) Analysis of relative gene expression data using real-time quantitative PCR and the 2(-Delta Delta $\mathrm{C}(\mathrm{T})$ ) method. Methods 25(4):402-408

Maddock IR, Moran A, Maher ER, Teare MD, Norman A, Payne SJ, Whitehouse R, Dodd C, Lavin M, Hartley N, others (1996) A genetic register for von Hippel-Lindau disease. J Med Genet 33(2):120-127

Maher ER, Kaelin WG Jr (1997) von Hippel-Lindau disease. Med (Baltimore) 76(6):381-391

Manski TJ, Heffner DK, Glenn GM, Patronas NJ, Pikus AT, Katz D, Lebovics R, Sledjeski K, Choyke PL, Zbar B, others (1997) Endolymphatic sac tumors. A source of morbid hearing loss in von Hippel-Lindau disease. JAMA 277(18):1461-1466

Martella M, Salviati L, Casarin A, Trevisson E, Opocher G, Polli R, Gross D, Murgia A (2006) Molecular analysis of two uncharacterized sequence variants of the VHL gene. J Hum Genet

Prowse AH, Webster AR, Richards FM, Richard S, Olschwang S, Resche F, Affara NA, Maher ER (1997) Somatic inactivation of the VHL gene in Von Hippel-Lindau disease tumors. Am J Hum Genet 60(4):765-771

Richards FM, Schofield PN, Fleming S, Maher ER (1996) Expression of the von Hippel-Lindau disease tumour suppressor gene during human embryogenesis. Hum Mol Genet 5(5):639-644

Skotheim RI, Diep CB, Kraggerud SM, Jakobsen KS, Lothe RA (2001) Evaluation of loss of heterozygosity/allelic imbalance scoring in tumor DNA. Cancer Genet Cytogenet 127(1):64-70

Stolle C, Glenn G, Zbar B, Humphrey JS, Choyke P, Walther M, Pack S, Hurley K, Andrey C, Klausner R, others (1998) Improved detection of germline mutations in the von Hippel-Lindau disease tumor suppressor gene. Hum Mutat 12(6):417-423

Teh BT, Blennow E, Giraud S, Sahlen S, Hii SI, Brookwell R, Brauch H, Nordenskjold M, Larsson C, Nicol D (1998). Bilateral multiple renal oncocytomas and cysts associated with a constitutional translocation $(8 ; 9)(\mathrm{q} 24.1 ; \mathrm{q} 34.3)$ and a rare constitutional VHL missense substitution. Genes Chromosomes Cancer 21(3):260-264

Tse JY, Wong JH, Lo KW, Poon WS, Huang DP, Ng HK (1997) Molecular genetic analysis of the von Hippel-Lindau disease tumor suppressor gene in familial and sporadic cerebellar hemangioblastomas. Am J Clin Pathol 107(4):459-466

Vandesompele J, De Preter K, Pattyn F, Poppe B, Van Roy N, De Paepe A, Speleman F (2002) Accurate normalization of real-time quantitative RT-PCR data by geometric averaging of multiple internal control genes. Genome Biol 3(7):RESEARCH0034

Vortmeyer AO, Gnarra JR, Emmert-Buck MR, Katz D, Linehan WM, Oldfield EH, Zhuang Z (1997) von Hippel-Lindau gene deletion detected in the stromal cell component of a cerebellar hemangioblastoma associated with von Hippel-Lindau disease. Hum Pathol 28(5):540-543

Webster AR, Richards FM, MacRonald FE, Moore AT, Maher ER (1998) An analysis of phenotypic variation in the familial cancer syndrome von Hippel-Lindau disease: evidence for modifier effects. Am J Hum Genet 63(4):1025-1035

Woodward ER, Buchberger A, Clifford SC, Hurst LD, Affara NA, Maher ER (2000) Comparative sequence analysis of the VHL tumor suppressor gene. Genomics 65(3):253-265

Zatyka M, Morrissey C, Kuzmin I, Lerman MI, Latif F, Richards FM, Maher ER (2002) Genetic and functional analysis of the von Hippel-Lindau (VHL) tumour suppressor gene promoter. J Med Genet 39(7):463-472 